\title{
Health on the Hill: Parliament mulls vaping regulations
}

\author{
— Cite as: CMAJ 2018 February 26;190:E232-3. doi: 10.1503/cmaj.109-5568
}

Posted on cmajnews.com on Feb.8, 2018.

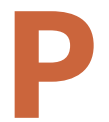

arliament debated new vaping rules and other public health bills in its first week back after winter break.

\section{Vaping and plain packaging}

Bill S-5 would update existing tobacco laws to regulate vaping products in much the same way as other tobacco products, including provisions to restrict sales to youth and ban flavoured products. The bill proposes to allow limited promotion of vaping products as a tool to help people quit smoking; however, it will prohibit claims of health benefits. "The key message that needs to be emphasized is that while scientific knowledge is still evolving on the issue, there is much more work to be done," said Kevin Lamoureux, Parliamentary Secretary to the Leader of the Government. "It is clear that vaping products may bring public health benefits, if they reduce tobacco-related death and disease by helping smokers quit or switch completely to a less harmful source of nicotine, but it may also harm young people, in particular."

The bill also would introduce plain packaging for tobacco and vaping products, replacing branding with health disclaimers and plain text. Conservative members took issue with this aspect of the proposed law, alleging that similar initiatives in Japan and France failed to reduce smoking. Liberals and New Democrats, conversely, cited the success of Australia's plain-packaging laws. "Many a study has been done, and we have seen that it has had a positive impact compared to previous packaging," said Lamoureux.

The bill passed second reading with only one no vote, and is now before the Standing Committee on Health.

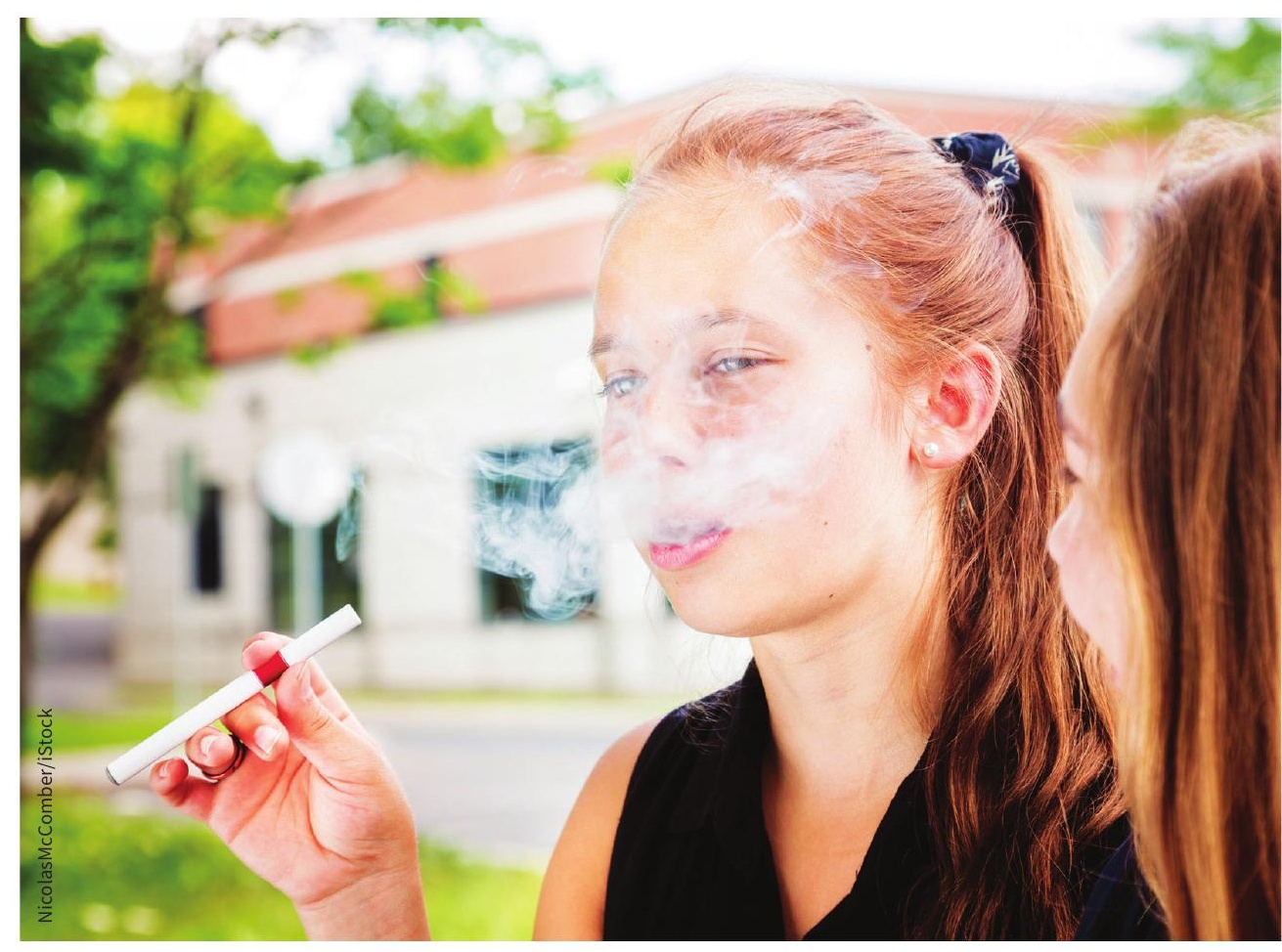

A Senate bill to restrict youth access to vaping products is before the Standing Committee on Health.

\section{Taxation}

Conservative MP Marilyn Gladu highlighted the "unintended consequences" of upcoming small-business tax reforms, arguing that people who own corporations, including many physicians, will be unable to afford to expand their businesses. She cited the example of a doctor in her riding of Sarnia-Lambton who uses the tax savings accumulated in his corporation to buy technology and expand his practice. Members also heard two petitions urging the government to reconsider the reforms, including one that called on the government to extend the consultation on the changes and "provide documentation that the Liberal government actually considered alternatives."
Joël Lightbound, Parliamentary Secretary to the Minister of Finance, said the reforms are necessary to "ensure a level playing field," and will affect only the richest $3 \%$ of private corporations. The government will present a detailed plan in the 2018 budget.

\section{Marijuana}

Bloc Québécois members raised concerns that the soon-to-be-legal marijuana market may be bankrolled by organized crime, noting that anonymous investors from known tax havens have sunk \$165 million into cannabis production. Health Minister Ginette Petitpas Taylor countered that the government's proposed cannabis bill will create a "responsible, well-regulated legal market." Petitpas Taylor also reiterated 
that the government will not decriminalize or legalize any other drugs aside from cannabis, in response to a call from New Democrat MP Don Davies to "abandon the failed war on drugs and adopt a health-based approach to addiction and drug use."

\section{End-of-life care and pharmacare}

Members also heard petitions urging the government to ensure access to palliative care and to protect the conscience rights of health professionals and institutions who do not wish to assist the deaths of patients. Other petitions called on the federal government to develop a universal, single-payer public drug plan under the Canada Health Act, and to provide coverage for the abortion medication Mifegymiso (mifepristone-misoprostol).
Disability benefits

The Liberal government voted down a bill that would create a single application process for all disability-related benefits, cutting red tape for people with disabilities and administrative burden for their health providers. Conservative and New Democrat members argued the current system requires people to prove they have a disability over and over, leading some doctors to turn these patients away. "They do not have the time to fill out the onerous paperwork that is required," explained Conservative MP Dan Albas. New Democrat MP Cheryl Hardcastle argued that "one process, one doctor's note" should be sufficient, and questioned whether the defeated bill "is only being turned down because it will be included in some sweeping legislation."
Automated external defibrillators

A bill that would equip all Royal Canadian Mounted Police vehicles with automated external defibrillators, or AEDS, also passed second reading. "The Heart and Stroke Foundation of Canada estimates that 40000 Canadians suffer from cardiac arrest each year, or one person every 13 minutes," said Liberal MP Julie Dabrusin. "In each of those instances, early access to a defibrillator can save a life." The bill won support across the aisle; however, NDP MP Matthew Dubé questioned why it delays the rollout of defibrillators until 12 months after the law is adopted. "There seems to be a lack of willingness to move this process along more quickly."

Lauren Vogel, CMAJ 